\title{
A cross-cultural adaptation and validation of the short-form McGill Pain Questionnaire-2: Chinese version in patients with chronic visceral pain
}

This article was published in the following Dove Press journal: Journal of Pain Research

5 January 2017

Number of times this article has been viewed

\author{
Jiang-Lin Wang ${ }^{1 *}$ \\ Wei-Jun Zhang2* \\ Min Gao ${ }^{2}$ \\ Shengfa Zhang ${ }^{2}$ \\ Dong-Hua Tian ${ }^{2 *}$ \\ Jun Chen ${ }^{1,3,4 *}$
}

'Institute for Biomedical Sciences of Pain, Tangdu Hospital, The Fourth Military Medical University, Xi'an, ${ }^{2}$ School of Social Development and Public policy, China Institute of Health, Beijing Normal University, Beijing, ${ }^{3}$ Key Laboratory of Brain Stress and Behavior, People's Liberation Army, Xi'an, ${ }^{4}$ Beijing Institute for Brain Disorders, Beijing, Peoples' Republic of China

* These authors contributed equally to this work
Correspondence: Jun Chen

Institute for Biomedical Sciences of Pain, Tangdu Hospital, The Fourth Military Medical University, No. 569 Xinsi Road, Baqiao, Xi'an 710038, People's Republic of China

Tel +86 2984777942

Fax +86298477 7945

Email junchen@fmmu.edu.cn

Dong-Hua Tian

School of Social Development and Public Policy, China Institute of Health, Beijing Normal University, 19, Xinjiekou Wai Street, Beijing 100875, People's Republic of China

Tel +86 I0 5880503 I

Fax +86 I0 58800366

Email tian65216@hotmail.com
Objective: The present study aimed to develop a culturally appropriate and functional Standard Mandarin Chinese translation of the short-form McGill Pain Questionnaire-2 (SF-MPQ-2) and to assess its reliability and validity for characterizing chronic visceral pain in Chinese patients. Background: The SF-MPQ-2 has been widely used in studies of pain epidemiology, diagnosis and treatment, and even pathophysiologic mechanisms to assess the major symptoms of clinical pain. Previous reports have shown favorable reliability, validity, and responsiveness of the SF-MPQ-2 in diverse samples of patients with chronic and acute pain. However, a culturally appropriate, functional Chinese version of the scale has never been developed.

Methods: Beaton's guidelines were used for the translation and back-translation procedures. Patients $(n=145)$ with chronic visceral pain were recruited to complete the Standard Mandarin Chinese version of the SF-MPQ-2 (SF-MPQ-2-CN), of which 41 were asked to complete the SF-MPQ-2-CN a second time, 3 days after the initial visit. The test-retest reliability was quantified using the intraclass correlation coefficient (ICC), and Cronbach's alpha was calculated to assess internal consistency. Possible components were determined by exploratory factor analysis with varimax rotation, and a value of 0.4 was considered requisite for the loading of each factor. Results: The ICC for subscales ranged from 0.909 to 0.952 , and that of the total scale was 0.927, suggesting excellent reliability and validity of the SF-MPQ-2-CN. Cronbach's alpha for subscales ranged from 0.896 to 0.916 , and that of the total scale was 0.836 and 0.831 for primary and secondary visits, respectively. The factor loading matrix of the SF-MPQ-2-CN ranged from 0.734 to 0.901 for each of the following subscales: continuous, intermittent, neuropathic, and affective, revealing four components similar to the original scale.

Conclusion: The reliability and validity of the SF-MPQ-2-CN scale are statistically acceptable for the evaluation of Chinese patients with chronic visceral pain.

Keywords: chronic visceral pain, Chinese version of short-form McGill Pain Questionnaire-2, exploratory factor analysis, reliability, validity

\section{Introduction}

The McGill Pain Questionnaire (MPQ) has been used for more than 30 years to evaluate the intensity, sensory, and affective aspects of pain. ${ }^{1,2}$ Its reliability and validity have been extensively documented. ${ }^{3}$ The short-form McGill Pain Questionnaire (SF-MPQ) is a simplified version of the MPQ that is less time consuming and includes 15 pain descriptors that have shown favorable reliability and validity. ${ }^{3,4}$ Although the SF-MPQ has been translated into several languages, such as Turkish, ${ }^{5}$ Greek, ${ }^{6}$ German, ${ }^{7}$ and French, ${ }^{8}$ the psychometric properties of each translation require further validation. ${ }^{9}$ The SF-MPQ has also been used to assess the patients with neuropathic pain; ${ }^{10}$ however, 
several symptoms reflecting mechanisms of neuropathic pain or those common in patients with neuropathic pain have not been included in the SF-MPQ. ${ }^{11}$ To address this problem, Dworkin et $\mathrm{al}^{11}$ developed the SF-MPQ-2 that included 22 descriptors of pain, thereby taking additional symptoms of neuropathic pain into account. ${ }^{11}$ Furthermore, a 4-point rating scale of the original SF-MPQ has been converted into a 0-10 numerical scale in the SF-MPQ-2, a modification that could provide better responsiveness. The SF-MPQ-2 has also been translated into Persian ${ }^{10}$ and Japanese. ${ }^{12}$

Pain is defined as an unpleasant sensory and emotional experience associated with actual or potential tissue damage, or described in terms of such damage. ${ }^{13}$ In addition, the American Pain Society has introduced the phrase "pain as the fifth vital sign". ${ }^{14}$ It is usually associated with impaired daily function and quality of life..$^{15,16}$ Similarly, pain has been a common burden of disease in China. ${ }^{17,18}$ Pain is reportedly a comorbid symptom of emotional and cognitive problems that can exacerbate the clinical condition of patients. ${ }^{19}$ Although a Chinese version of the Brief Pain Inventory has been recommended for pain assessment ${ }^{18,20,21}$ and some small sample studies have been reported, ${ }^{20-26}$ generally, the studies on pain in China have not been effectively conducted because of a lack of validated methods and tools. Thus, we attempted to develop a culturally appropriate and functional Chinese version of the SF-MPQ-2 and to evaluate its reliability and validity to measure chronic pain in Chinese patients.

\section{Materials and methods}

\section{Instrument}

\section{The SF-MPQ-2}

The SF-MPQ-2, a scale that was self-rated by subjects according to the intensity of pain perceived on a $0-10$ numeric scale ( $0=$ no pain and $10=$ the worst pain), is composed of 22 pain descriptors and four subscales. It included six continuous pain descriptors (throbbing, cramping, gnawing, aching, heavy pain, and tender), six intermittent pain descriptors (shooting, stabbing, sharp, splitting, electric-shock pain, and piercing), six predominantly non-neuropathic pain descriptors (hot-burning and cold-freezing pain, pain caused by light touch, itching, tingling or pins and needles, and numbness), and four affective descriptors (tiring-exhausting, sickening, fearful, and punishing-cruel). ${ }^{11,27}$ The four subscale scores were calculated by summating the numerical values of each item, and the total scores represented the sum of values for all 22 items. ${ }^{11,27}$ Higher subscale or total scale scores indicated patients with more intense symptoms.

\section{Translation and procedures}

To obtain a Chinese version of the SF-MPQ-2, multiple translation procedures were performed according to Beaton's guidelines that have been used for cross-cultural adaptation of health-related questionnaires. ${ }^{28}$ The SF-MPQ-2 was translated into Standard Mandarin Chinese (SF-MPQ-2-CN) by two translators (one is a neuroscientist and the other is a physician specializing in pain medicine). These two translators independently produced two primary SF-MPQ-2 Chinese versions. A third reconciled version was then completed based on a comparison of the former two versions. The fourth version was a translation of the Chinese version back into English and was produced by two additional translators, who had no knowledge of the contents of the original questionnaire. Any discrepancies in the fourth version from these two translators were resolved in the fifth version (the SF-MPQ-2-CN used in the present study) by an expert committee of the Institute for Functional Brain Disorders and Institute for Biomedical Sciences of Pain at Fourth Military Medical University. In order to determine the readability and understandability of the preliminary SF-MPQ-2-CN (Supplementary material), it was eventually distributed in a pilot study to 79 patients with chronic pain, who were asked about any unclear words, phrases, or concepts. The results of the pilot study showed that the SF-MPQ-2-CN was easily understood by the subjects without significant complaints.

\section{Participants}

On the basis of the results of previous studies, ${ }^{29,30}$ the minimum sample size in factor analysis should be at least 100 or the minimum ratio of sample size to the number of variables should be 5:1. Specifically, for the present study, at least 110 subjects should have been included, based on the number of items on the SF-MPQ-2-CN. In the present study, 145 patients aged $>50$ years were recruited from the Pain Clinic at the Geriatric Hospital of Hebei Province (Shijiazhuang, China) and the Department of Internal Neurology at Bethune International Peace Hospital of the People's Liberation Army (Shijiazhuang, China), by the convenience sampling method between the months of June and November 2015. Inclusion criteria included the following: an ability to speak and read Chinese, visceral pain for more than 3 weeks, and willingness to cooperate with the investigators and sign an informed consent form. Exclusion criteria included the following: intellectual disability, psychosis, or dementia; patient refusal; and inability to communicate in Standard Mandarin Chinese. The demographic data including gender, age, educational level, marital status, and employment status were also recorded 
(Table 1). Pain was diagnosed and classified by pain physicians, according to the Chinese version of the International Classification of Disease, Eleventh Revision (ICD-11) ${ }^{31}$ that was translated from the recently published article "A classification of chronic pain for ICD-11". ${ }^{32}$ All patients were approached by their attending doctors or nurses. A pilot study was conducted on 30 patients with chronic visceral pain to test the consensus of the SF-MPQ-2-CN. Another 145 patients with chronic visceral pain were then recruited and asked to complete the final version of the SF-MPQ-2-CN. Of this number, 41 patients were asked to complete the SFMPQ-2-CN a second time, 3 days after the initial visit.

\section{Statistical analysis}

Continuous data were expressed as mean and standard deviations (SDs), and categorical data were expressed as frequencies and percentages. The internal consistency of each subscale of the SF-MPQ-2-CN was evaluated using Cronbach's alpha coefficient, and a value $>0.80$ was considered satisfactory. ${ }^{33}$ Reliability was determined using the intraclass correlation coefficient (ICC), and a value $>0.70$ was considered adequate. ${ }^{33}$ Moreover, the validity of the scale was also assessed by calculating the correlations between total scores and subscale scores of the patients. Only absolute correlation values $>0.40$ and $p$-values $<0.05$ were considered statistically significant. Finally, the possible components were determined

Table I Characteristics of patients with chronic visceral pain

\begin{tabular}{|c|c|}
\hline Age (mean $\pm S D)$ & $63.87 \pm 8.99$ \\
\hline \multicolumn{2}{|l|}{ Gender, n (\%) } \\
\hline Male & $86(59.31)$ \\
\hline Female & $59(40.69)$ \\
\hline \multicolumn{2}{|l|}{ Registered residence, $\mathbf{n}(\%)$} \\
\hline Rural residents & $56(38.62)$ \\
\hline Urban residents & $89(61.38)$ \\
\hline \multicolumn{2}{|l|}{ Education, n (\%) } \\
\hline Junior level ( $<6$ years old) & $52(36.11)$ \\
\hline High school level ( $>6$ and $<12$ years old) & $52(36.11)$ \\
\hline College or a higher level (>12 years old) & $4 \mid(28.47)$ \\
\hline \multicolumn{2}{|l|}{ Marital status, $\mathbf{n}(\%)$} \\
\hline Married & $125(86.81)$ \\
\hline Divorced & $8(5.56)$ \\
\hline Widowed & $7(4.86)$ \\
\hline Unmarried & $3(2.08)$ \\
\hline Separated & $2(1.69)$ \\
\hline \multicolumn{2}{|l|}{ Employment status, $\mathbf{n}(\%)$} \\
\hline Employed & $84(57.93)$ \\
\hline Retired & $42(28.97)$ \\
\hline Disabled & $14(9.65)$ \\
\hline Unemployed & $5(3.45)$ \\
\hline Duration of pain (years, mean \pm SD) & $7.5 \mathrm{I} \pm 8.28$ \\
\hline
\end{tabular}

Abbreviation: SD, standard deviation. by exploratory factor analysis (EFA) with varimax rotation, and a value of 0.4 was considered requisite for the loading of each factor. ${ }^{34,35}$ Specifically, principal component analysis was used as the method of factor analysis. The software SPSS v21 (IBM Corporation, Armonk, NY) was used for statistical analyses in the present study. In addition, confirmatory factor analysis (CFA) was performed using the IBM SPSS Amos 21 software (IBM Corporation).

\section{Ethics approval and consent to participate}

The study was approved by the Institutional Review Board at the School of Social Development and Public Policy at the Beijing Normal University and the Research Oversight Committee of Fourth Military Medical University. All subjects provided written informed consent.

\section{Results}

\section{Sample characteristics}

As shown in Table 1, 145 patients with an average age of 63.87 years (SD 8.99) participated in the study, with an age range of 50-89 years. The total sample included 59 (40.69\%) females and $86(59.31 \%)$ males. Most of the participants were urban residents $(61.38 \%)$, and the others were rural residents $(38.62 \%)$. The duration of pain ranged from 1 to 40 years, with a mean of $7.51 \pm 0.69$ years. Among the participants, $86.81 \%$ were married and living with their partners, whereas the others were divorced (5.56\%), widowed $(4.86 \%)$, unmarried $(2.08 \%)$, or separated $(1.69 \%)$. Out of all the participants, $28.47 \%$ graduated from college or a higher level of education; $36.11 \%$ completed technical, secondary, or high school; and another $36.11 \%$ attended school up to a primary education level (junior middle school level and below; Table 1). It was noteworthy that the number of employed subjects was $57.93 \%$, representing the highest ratio of all subjects. The other occupational categories included those who were retired (28.97\%), disabled (9.65\%), or unemployed $(3.45 \%$; Table 1$)$.

\section{Reliability analysis}

The ICC for 22 individual items was highly correlated between the test-retest, with a range from 0.819 (aching pain) to 0.994 (tingling or "pins and needles"; Table 2). Moreover, the ICC for subscales of the SF-MPQ-2-CN indicated excellent reliability between the test-retest (Table 3). Furthermore, the ICC for the total SF-MPQ-2-CN also presented excellent reliability with a value of 0.927 (Table 3). Cronbach's alpha coefficient also revealed good internal consistency for the 
Table 2 ICC between the test-retest of the SF-MPQ-2-CN

\begin{tabular}{|c|c|c|c|c|c|c|c|}
\hline Item & Domain & Original SF-MPQ-2 & TI $(n=144)$ mean \pm SD & $T 2(n=44)$ mean $\pm S D$ & ICC & $95 \% \mathrm{Cl}$ & $p$-Value \\
\hline 1 & Continuous & Throbbing pain & $4.2 \pm 2.58$ & $3.5 \pm 1.80$ & 0.878 & $0.77 I-0.935$ & $<0.001$ \\
\hline 2 & Intermittent & Shooting pain & $3.84 \pm 2.41$ & $4.39 \pm 2.45$ & 0.972 & $0.947-0.985$ & $<0.001$ \\
\hline 3 & Intermittent & Stabbing pain & $3.69 \pm 2.42$ & $3.93 \pm 2.28$ & 0.952 & $0.910-0.974$ & $<0.001$ \\
\hline 4 & Intermittent & Sharp pain & $3.73 \pm 2.54$ & $4.24 \pm 2.10$ & 0.930 & $0.869-0.963$ & $<0.001$ \\
\hline 5 & Continuous & Cramping pain & $4.7 \pm 2.50$ & $3.7 I \pm 1.63$ & 0.910 & $0.832-0.952$ & $<0.001$ \\
\hline 6 & Continuous & Gnawing pain & $4.03 \pm 2.79$ & $3.63 \pm 1.71$ & 0.847 & $0.714-0.919$ & $<0.001$ \\
\hline 7 & Neuropathic & Hot-burning pain & $3.95 \pm 2.52$ & $3.88 \pm 2.23$ & 0.958 & $0.922-0.978$ & $<0.001$ \\
\hline 8 & Continuous & Aching pain & $4.1 I \pm 2.72$ & $3.49 \pm 1.50$ & 0.819 & $0.66 \mathrm{I}-0.904$ & $<0.001$ \\
\hline 9 & Continuous & Heavy pain & $4.25 \pm 2.45$ & $4.15 \pm 1.75$ & 0.867 & $0.75 I-0.929$ & $<0.001$ \\
\hline 10 & Continuous & Tender & $4.38 \pm 2.49$ & $2.88 \pm 1.85$ & 0.875 & $0.765-0.933$ & $<0.001$ \\
\hline 11 & Intermittent & Splitting pain & $3.65 \pm 2.40$ & $4.39 \pm 1.58$ & $0.84 I$ & $0.702-0.915$ & $<0.001$ \\
\hline 12 & Affective & Tiring-exhausting & $4.09 \pm 2.69$ & $4.63 \pm 2.23$ & 0.942 & $0.891-0.969$ & $<0.001$ \\
\hline 13 & Affective & Sickening & $3.88 \pm 2.84$ & $4.66 \pm 2.40$ & 0.913 & $0.837-0.954$ & $<0.001$ \\
\hline 14 & Affective & Fearful & $4.14 \pm 2.76$ & $4.73 \pm 2.07$ & 0.938 & $0.885-0.967$ & $<0.001$ \\
\hline 15 & Affective & Punishing-cruel & $4.01 \pm 2.92$ & $4.49 \pm 2.43$ & 0.946 & $0.898-0.971$ & $<0.001$ \\
\hline 16 & Intermittent & Electric-shock pain & $3.87 \pm 2.34$ & $4.21 \pm 1.75$ & 0.934 & $0.876-0.965$ & $<0.001$ \\
\hline 17 & Neuropathic & Cold-freezing pain & $4.0 \mathrm{I} \pm 2.50$ & $3.85 \pm 2.14$ & 0.940 & $0.887-0.968$ & $<0.001$ \\
\hline 18 & Intermittent & Piercing & $4.23 \pm 2.5 \mathrm{I}$ & $4.29 \pm 1.99$ & 0.964 & $0.932-0.981$ & $<0.001$ \\
\hline 19 & Neuropathic & Pain caused by light touch & $4.17 \pm 2.58$ & $3.85 \pm 1.94$ & 0.951 & $0.907-0.974$ & $<0.001$ \\
\hline 20 & Neuropathic & Itching & $4.08 \pm 2.55$ & $4.00 \pm 2.4 \mathrm{I}$ & 0.961 & $0.926-0.979$ & $<0.001$ \\
\hline 21 & Neuropathic & Tingling or "pins and needles" & $3.90 \pm 2.58$ & $3.66 \pm 2.45$ & 0.994 & $0.989-0.997$ & $<0.001$ \\
\hline 22 & Neuropathic & Numbness & $4.14 \pm 2.84$ & $3.93 \pm 2.43$ & 0.982 & $0.965-0.990$ & $<0.001$ \\
\hline
\end{tabular}

Abbreviations: $\mathrm{Cl}$, confidence interval; ICC, intraclass correlation coefficient; SF-MPQ-2-CN, Chinese version of short-form McGill Pain Questionnaire-2; SD, standard deviation; $\mathrm{TI}$, test; $\mathrm{T} 2$, retest.

Table 3 Internal consistency and test-retest reliability of the SF-MPQ-2-CN

\begin{tabular}{|c|c|c|c|c|c|c|c|c|c|}
\hline \multirow[t]{2}{*}{ Subscale } & \multirow{2}{*}{$\begin{array}{l}\text { Number } \\
\text { of items }\end{array}$} & \multirow{2}{*}{$\begin{array}{l}\text { Item number } \\
\text { of original } \\
\text { SF-MPQ-2 }\end{array}$} & \multirow{2}{*}{$\begin{array}{l}\text { TI }(n=I 44) \\
\text { mean } \pm S D\end{array}$} & \multirow{2}{*}{$\begin{array}{l}\text { T2 }(n=4 I) \\
\text { mean } \pm S D\end{array}$} & \multirow{2}{*}{\multicolumn{2}{|c|}{$\begin{array}{l}\text { Cronbach's } \\
\text { alpha (TI, T2) }\end{array}$}} & \multicolumn{3}{|l|}{ ICC } \\
\hline & & & & & & & ICC & $95 \% \mathrm{Cl}$ & $p$-Value \\
\hline Continuous & 6 & $1,5,6,8,9,10$ & $25.68 \pm 12.60$ & $21.31 \pm 7.87$ & 0.896 & 0.859 & 0.909 & $0.829-0.951$ & $<0.001$ \\
\hline Intermittent & 6 & $2,3,4,11,16,18$ & $23.01 \pm 12.56$ & $25.46 \pm 10.44$ & 0.929 & 0.923 & 0.973 & $0.949-0.985$ & $<0.001$ \\
\hline Neuropathic & 6 & $7,17,19,20,21,22$ & $24.25 \pm 13.30$ & $23.17 \pm 12.14$ & 0.926 & 0.948 & 0.988 & $0.977-0.993$ & $<0.001$ \\
\hline Affective & 4 & $12,13,14,15$ & $16.11 \pm 10.02$ & $|8.5| \pm 8.20$ & 0.916 & 0.917 & 0.952 & $0.911-0.975$ & $<0.001$ \\
\hline Total & 22 & & $72.95 \pm 21.56$ & $88.46 \pm 21.28$ & 0.836 & 0.831 & 0.927 & $0.862-0.961$ & $<0.001$ \\
\hline
\end{tabular}

Abbreviations: $\mathrm{Cl}$, confidence interval; ICC, intraclass correlation coefficient; SF-MPQ-2-CN, Chinese version of short-form McGill Pain Questionnaire-2; SD, standard deviation; T1, test; T2, retest.

total scale and subscales of the SF-MPQ-2-CN at the primary and secondary visits, respectively (Table 3 ).

\section{Factor structure}

The EFA showed that the Kaiser-Meyer-Olkin value of the SF-MPQ-2-CN was 0.866, and four components with a variance of $73.55 \%$ were extracted (Table 4 ) that were comparable with the original SF-MPQ-2-CN subscales of continuous, intermittent, neuropathic, and affective. The value of each factor loading was $>0.4$. Conventionally, these factors were considered as major constituents (Table 4). In addition, the CFA model with which the four subscales of the SF-MPQ-2-CN were tested is presented in Table 5. The goodness of fit index (GFI) and normed fit index (NFI) for the model are also shown. The factor structures and related coefficients are presented in Figure 1. As shown in Table 5, the model fit index, GFI, and NFI for the four subscales were $>0.90$, indicating an acceptable fit. Whereas another index, the root-mean-square error of approximation (RMSEA) was 0.088 and 0.121 for intermittent and affective subscales, respectively, indicating poor fit owing to those values that were $>0.08$.

\section{Discussion}

In this study, we most likely provided the first report of the validity and reliability of the SF-MPQ-2-CN for the 
Table 4 Factor loading matrix of SF-MPQ-2 (variance maximizing rotation)

\begin{tabular}{|c|c|c|c|c|c|}
\hline Item & Original SF-MPQ-2 & Continuous & Intermittent & Neuropathic & Affective \\
\hline I & Throbbing pain & 0.772 & 0.017 & 0.100 & 0.037 \\
\hline 5 & Cramping pain & 0.825 & 0.132 & 0.014 & 0.132 \\
\hline 6 & Gnawing pain & 0.734 & -0.011 & 0.261 & 0.125 \\
\hline 8 & Aching pain & 0.850 & -0.107 & -0.016 & 0.166 \\
\hline 9 & Heavy pain & $0.8 \mathrm{II}$ & -0.033 & 0.044 & 0.200 \\
\hline 10 & Tender & 0.768 & -0.147 & 0.074 & 0.228 \\
\hline 2 & Shooting pain & -0.005 & 0.865 & -0.138 & 0.067 \\
\hline 3 & Stabbing pain & 0.042 & 0.864 & -0.176 & 0.046 \\
\hline 4 & Sharp pain & -0.029 & 0.855 & -0.044 & -0.018 \\
\hline II & Splitting pain & -0.020 & 0.843 & -0.104 & 0.093 \\
\hline 16 & Electric-shock pain & -0.124 & 0.794 & -0.131 & 0.112 \\
\hline 18 & Piercing & 0.009 & 0.869 & 0.009 & 0.142 \\
\hline 7 & Hot-burning pain & -0.014 & -0.111 & 0.821 & 0.033 \\
\hline 17 & Cold-freezing pain & 0.121 & -0.090 & 0.839 & 0.140 \\
\hline 19 & Pain caused by light touch & 0.154 & -0.151 & 0.834 & -0.006 \\
\hline 20 & Itching & 0.033 & -0.098 & 0.865 & -0.003 \\
\hline 21 & Tingling or "pins and needles" & 0.122 & -0.058 & $0.86 I$ & -0.005 \\
\hline 22 & Numbness & 0.045 & -0.106 & 0.843 & 0.028 \\
\hline 12 & Tiring-exhausting & 0.230 & 0.094 & 0.004 & 0.866 \\
\hline 13 & Sickening & 0.163 & 0.072 & 0.010 & 0.901 \\
\hline 14 & Fearful & 0.195 & 0.064 & 0.039 & 0.874 \\
\hline 15 & Punishing-cruel & 0.192 & 0.184 & 0.114 & 0.817 \\
\hline $\mathrm{KMO}$ value & 0.866 & & & & \\
\hline $\begin{array}{l}\text { The extraction sums of } \\
\text { squared loading }\end{array}$ & 73.75 & & & & \\
\hline
\end{tabular}

Note: Bartlett's test value $=2280.412$ and $P$-value $<0.001$.

Abbreviations: SF-MPQ-2, short-form McGill Pain Questionnaire-2; KMO, Kaiser-Meyer-Olkin.

Table 5 CFA of the SF-MPQ-2-CN subscales

\begin{tabular}{lllllllll}
\hline SF-MPQ-2-CN subscales & GFI & RMSEA & NFI & RFI & RMR & Chi-square & Degrees of freedom & p-Value \\
\hline Continuous & 0.967 & 0.07 & 0.967 & 0.995 & 0.182 & 15.373 & 9 & 0.081 \\
Intermittent & 0.957 & 0.088 & 0.97 & 0.951 & 0.149 & 18.940 & 9 & 0.026 \\
Neuropathic & 0.975 & 0.042 & 0.982 & 0.969 & 0.131 & 11.244 & 9 & 0.259 \\
Affective & 0.952 & 0.213 & 0.965 & 0.895 & 0.023 & 14.991 & 2 & 0.001 \\
\hline
\end{tabular}

Notes: Acceptable fit of the CFA analysis solutions was evaluated based on both GFI and NFI $\geq 0.90$ was considered acceptable; SRMR $\leq 0.08$ was considered acceptable. Abbreviations: CFA, confirmatory factor analysis; GFI, goodness of fit index; NFI, normed fit index; RFI, relative fit index; RMSEA, root-mean-square error of approximation; RMR, root-mean-square residual; SF-MPQ-2-CN, Chinese version of short-form McGill Pain Questionnaire-2.

evaluation of patients with chronic or subacute visceral pain in certain Chinese populations. The reliability and validity of the SF-MPQ-2-CN for patients with chronic visceral pain were confirmed using internal consistency analysis and the EFA, respectively. Furthermore, Cronbach's alpha coefficients indicated internal consistency (Table 3), a finding that is consistent with the results of the original study conducted by Dworkin et al. ${ }^{11}$ Furthermore, the construct validity of the SF-MPQ-2-CN was also found to be satisfactory. The ICC, calculated by the test-retest method, also indicated excellent reliability, with values of $0.909,0.973$, $0.988,0.952$, and 0.927 , for the continuous, intermittent, predominantly neuropathic, and affective subscales and the total scale, respectively. These values were higher than those previously reported by researchers in Japan and Iran, using scales in their respective native languages. ${ }^{10,12}$ The results of the present study were consistent with those of the original English version of the SF-MPQ-2 that yielded values ranging from 0.73 to $0.95^{11}$ and those of two translations in Iranian $(0.941)^{10}$ and Japanese (0.83). ${ }^{12}$ These findings suggest that the original English version of the SF-MPQ-2 can be crossculturally applied in different languages for the evaluation of clinical pain.

In addition, the EFA was conducted to demonstrate the variability among the 22 items of the SF-MPQ-2-CN. Four components (continuous, intermittent, predominantly 


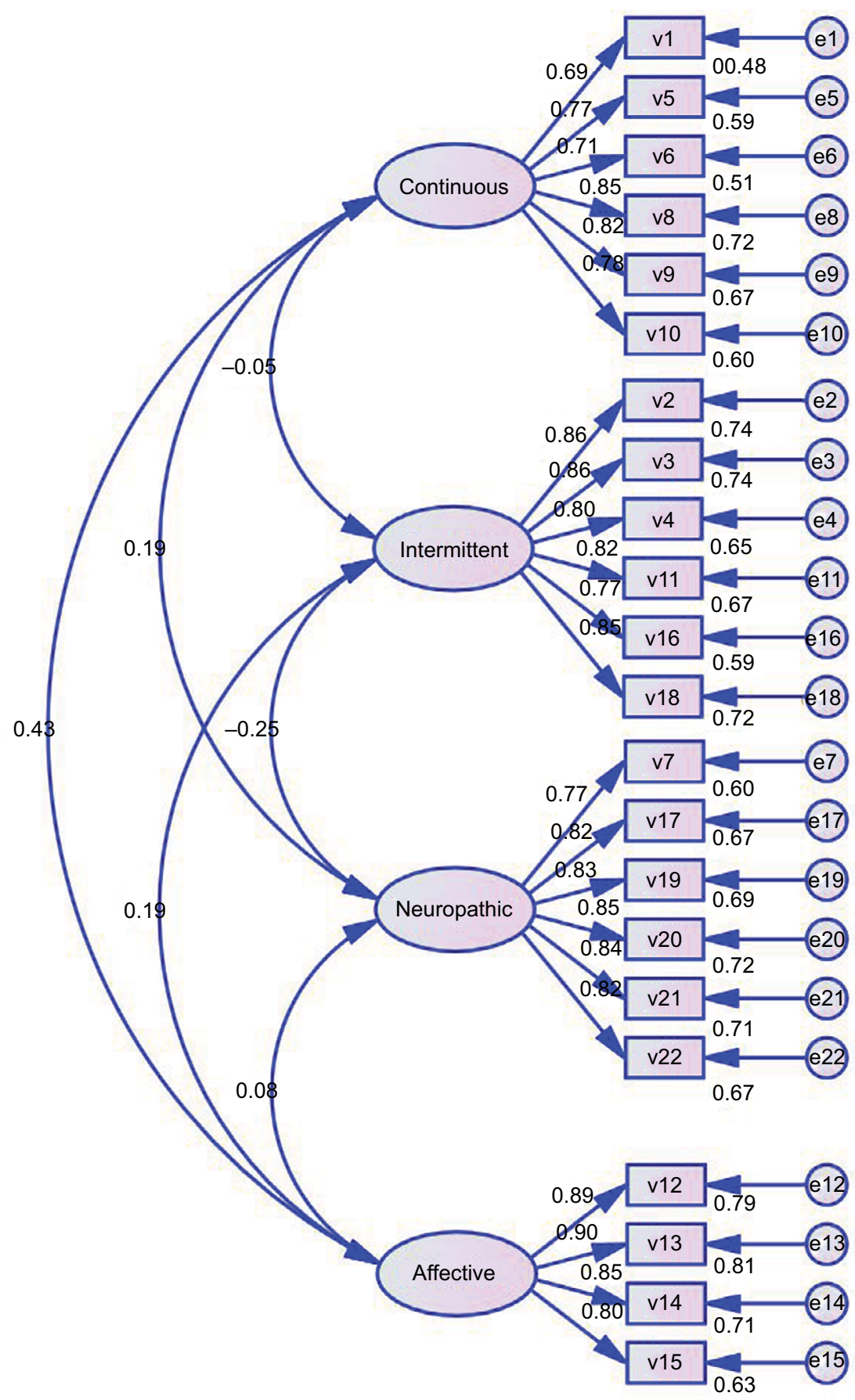

Figure I The factor structures for SF-MPQ-2 continuous, intermittent, neuropathic, and affective subscales.

Notes: The variables $\mathrm{vl}-\mathrm{v} 22$ indicate throbbing, cramping pain, gnawing pain, aching pain, heavy pain, tender, shooting pain, stabbing pain, sharp pain, splitting pain, electricshock pain, piercing, hot-burning pain, cold-freezing pain, pain caused by light touch, itching, tingling or "pins and needles," numbness, tiring-exhausting, sickening, fearful, punishing-cruel, respectively.

neuropathic, and affective) were extracted with a variance of $73.55 \%$, a finding that is consistent with those of the original version of the SF-MPQ-2 (Table 4). Moreover, the RMSEA, a CFA model index for intermittent and affective subscales, showed a poor fit, similar to the results of a previous study on patients with acute low back pain. ${ }^{27}$ The reasons for this bias remain unknown and require further analysis.
It was indeed difficult to use the SF-MPQ-2-CN to evaluate the patients with pain countrywide, unless they spoke Mandarin. There was a large variety of dialects across various regions and a wide range of educational levels from urban and rural areas. Further efforts should be made to adapt the SF-MPQ-2-CN by language modification and simplification and to broaden the availability of pain assessment across a larger population in China. Moreover, chronic pain was 
classified into seven groups in the ICD-11, including primary pain, cancer pain, postsurgical and posttraumatic pain, neuropathic pain, headache and orofacial pain, visceral pain, and musculoskeletal pain. ${ }^{31,32}$ Evaluation of the validity and sensitivity of the SF-MPQ-2-CN in Chinese patients with various classes of chronic pain would be necessary and useful. Because the SF-MPQ-2-CN is not specific for the assessment of neuropathic pain, translation and validation of neuropathic pain assessment tools in Standard Mandarin Chinese language is of critical importance. ${ }^{36-38}$

Several limitations existed in the present study. First, the sample size was relatively small and this might have influenced the results. Second, the analyzed sample included only patients with chronic visceral pain. Therefore, comparisons with other types of pain were not possible.

In conclusion, the reliability and validity of the SF-MPQ2-CN were confirmed in patients with chronic visceral pain in China. The SF-MPQ-2-CN is a promising scale that can be used as a general tool in medical research and routine clinical practice for pain assessment in China. The present study provided new evidence for cross-cultural application of the original SF-MPQ-2.

\section{Acknowledgments}

The authors are grateful to the Geriatric Hospital of Hebei Province, Bethune International Peace Hospital of the People's Liberation Army (PLA), and data collectors for their support and to all respondents for their participation in the study. This work was supported by the National Key Technology R\&D Program (2013BAI04B04) and the Twelfth Five-Year Project (AWS12J004) to JC.

\section{Author contributions}

W-JZ, J-LW, D-HT, and JC were involved in study design and research instrument development. W-JZ and J-LW were involved in data analysis and wrote the manuscript. SZ and MG were involved in data collection and data scrubbing. All authors contributed toward data analysis, drafting and revising the paper and agree to be accountable for all aspects of the work.

\section{Disclosure}

The authors report no conflicts of interest in this work.

\section{References}

1. Melzack R. The McGill pain questionnaire: major properties and scoring methods. Pain. 1975;1(3):277-299.

2. Melzack R. The McGill pain questionnaire: from description to measurement. Anesthesiology. 2005;103(1):199-202.

3. Turk DC, Melzack R. Handbook of Pain Assessment. 3rd ed. New York, NY: Guilford Press; 2011.
4. Melzack R. The short-form McGill Pain Questionnaire. Pain. 1987;30(2): 191-197.

5. Bogduk N. On the definitions and physiology of back pain, referred pain, and radicular pain. Pain. 2009;147(1-3):17-19.

6. Bjelland I, Dahl AA, Haug TT, Neckelmann D. The validity of the Hospital Anxiety and Depression Scale. An updated literature review. J Psychosom Res. 2002;52(2):69-77.

7. Bouhassira D, Attal N, Alchaar H, et al. Comparison of pain syndromes associated with nervous or somatic lesions and development of a new neuropathic pain diagnostic questionnaire (DN4). Pain. 2005;114(1-2):29-36.

8. Bouhassira D, Attal N, Fermanian J, et al. Development and validation of the Neuropathic Pain Symptom Inventory. Pain. 2004;108(3):248-257.

9. Cleeland CS, Ryan KM. Pain assessment: global use of the Brief Pain Inventory. Ann Acad Med Singapore. 1994;23(2):129-138.

10. Adelmanesh F, Jalali A, Attarian H, Farahani B, Ketabchi SM, Arvantaj A, Raissi GR. Reliability, validity, and sensitivity measures of expanded and revised version of the short-form McGill Pain Questionnaire (SFMPQ-2) in Iranian patients with neuropathic and non-neuropathic pain. Pain Med. 2012;13(12):1631-1636.

11. Dworkin RH, Turk DC, Revicki DA, et al. Development and initial validation of an expanded and revised version of the Short-form McGill Pain Questionnaire (SF-MPQ-2). Pain. 2009;144(1-2):35-42.

12. Maruo T, Nakae A, Maeda L, et al. Validity, reliability, and assessment sensitivity of the Japanese version of the short-form McGill pain questionnaire 2 in Japanese patients with neuropathic and non-neuropathic pain. Pain Med. 2014;15(11):1930-1937.

13. Merskey H, Bogduk N. Classification of Chronic Pain: Descriptions of Chronic Pain Syndromes and Definitions of Pain Terms. 2nd ed. Seattle: International Association for the Study of Pain (IASP) Press; 1994.

14. Lynch M. Pain as the fifth vital sign. J Intraven Nurs. 2001;24(2):85-94.

15. McNeill JA, Sherwood GD, Starck PL, Thompson CJ. Assessing clinical outcomes: patient satisfaction with pain management. J Pain Symptom Manage. 1998;16(1):29-40.

16. Liao Z, Hao J, Guo Y, Reyes-Gibby C, Guo H. Assessment of cancer pain management knowledge in southwest China: a survey of 259 physicians from small city and county hospitals. J Palliat Med. 2013;16(6):692-695.

17. Peng LH, Jing JY, Qin PP, Su M. A Multi-centered Cross-sectional Study of Disease Burden of Pain of Inpatients in Southwest China. Chinese Med J. 2016;129(8):936-941.

18. Global Burden of Disease Study Collaborators. Global, regional, and national incidence, prevalence, and years lived with disability for 301 acute and chronic diseases and injuries in 188 countries, 1990-2013: a systematic analysis for the Global Burden of Disease Study 2013. Lancet. 2015;386(9995):743-800.

19. Wang XS, Li TD, Yu SY, Gu WP, Xu GW. China: status of pain and palliative care. J Pain Symptom Manage. 2002;24(2):177-179.

20. Zhao F, Tsay JY, Cheng XM, et al. Epidemiology of migraine: a survey in 21 provinces of the People's Republic of China, 1985. Headache. 1988;28(8):558-565.

21. Zeng QY, Chen R, Xiao ZY, et al. Low prevalence of knee and back pain in southeast China; the Shantou COPCORD study. J Rheumatol. 2004;31(12):2439-2443.

22. Jin K, Sorock GS, Courtney TK. Prevalence of low back pain in three occupational groups in Shanghai, People's Republic of China. J Safety Res. 2004;35(1):23-28.

23. Smith DR, Wei N, Kang L, Wang RS. Musculoskeletal disorders among professional nurses in mainland China. J Prof Nurs. 2004;20(6): 390-395.

24. Gureje O, Von Korff M, Simon GE, Gater R. Persistent pain and wellbeing: a World Health Organization Study in Primary Care. JAMA. 1998;280(2):147-151.

25. Jackson T, Chen H, Iezzi T, Yee M, Chen F. Prevalence and correlates of chronic pain in a random population study of adults in Chongqing, China. Clin J Pain. 2014;30(4):346-352.

26. Wang XS, Mendoza TR, Gao SZ, Cleeland CS. The Chinese version of the Brief Pain Inventory (BPI-C): its development and use in a study of cancer pain. Pain. 1996;67(2-3):407-416. 
27. Dworkin RH, Turk DC, Trudeau JJ, Benson C, Biondi DM, Katz NP, Kim M. Validation of the short-form McGill Pain questionnaire-2 (SFMPQ-2) in acute low back pain. J Pain. 2015;16(4):357-366.

28. Beaton DE, Bombardier C, Guillemin F, Ferraz MB. Guidelines for the process of cross-cultural adaptation of self-report measures. Spine. 2000;25(24):3186-3191.

29. Gorsuch RL. Factor Analysis. 2nd ed. Hillsdale, NJ: Erlbaum; 1983.

30. MacCallum RC, Widaman KF, Zhang S, Hong S. Sample size in factor analysis. Psychol Methods. 1999;4(1):84-99.

31. Hu L, Luo C, Chen J. A classification of chronic pain for ICD-11. Chin J Pain Med. 2015;21(07):486-488. (Chinese translation from Ref. 32).

32. Treede RD, Rief W, Barke A, et al. A classification of chronic pain for ICD-11. Pain. 2015;156(6):1003-1007.
33. Nunnally J, Bernstein I. Psychometric Theory. 3rd ed. New York, NY: McGraw-Hill; 1994.

34. Stevens JP. Applied Multivariate Statistics for the Social Sciences. 2nd ed. Hillsdale, NJ: Erlbaum; 1992.

35. Ferguson E, Cox T. Exploratory factor analysis: a users' guide. Int $J$ Select Assess. 1993;1(2):84-94.

36. Galer BS, Jensen MP. Development and preliminary validation of a pain measure specific to neuropathic pain: the Neuropathic Pain Scale. Neurology. 1997;48(2):332-338.

37. Backonja MM, Stacey B. Neuropathic pain symptoms relative to overall pain rating. J Pain. 2004;5(9):491-497.

38. Krause SJ, Backonja MM. Development of a neuropathic pain questionnaire. Clin J Pain. 2003;19(5):306-314.

\section{Publish your work in this journal}

The Journal of Pain Research is an international, peer reviewed, open access, online journal that welcomes laboratory and clinical findings in the fields of pain research and the prevention and management of pain. Original research, reviews, symposium reports, hypothesis formation and commentaries are all considered for publication.

\section{Dovepress}

The manuscript management system is completely online and includes a very quick and fair peer-review system, which is all easy to use. Visit http://www.dovepress.com/testimonials.php to read real quotes from published authors. 